\title{
METHANE POTENTIAL AND RESPIRATION INTENSITY OF WASTES AND AGRICULTURAL BYPRODUCTS
}

\author{
UVEGES, Zs. ${ }^{12^{*}}$ - RAGONCZA, Á. ${ }^{3}-$ VARGA, Zs. ${ }^{4}-$ ALEKSZA, L. ${ }^{4}$ \\ ${ }^{1}$ Institute of Agricultural Engineering, National Agricultural Research and Innovation Centre \\ (NARIC IAE), Tessedik Sámuel 4., Gödöllö 2100, Hungary
}

${ }^{2}$ Doctoral School of Environmental Sciences, Szent Istvan University (SZIU), Páter Károly 1., Gödöllö 2100, Hungary

${ }^{3}$ Nawaro Inc., Szabadság sq. 1., Gödöllö 2100, Hungary

(e-mail: adam.ragoncza@nawaro.hu)

${ }^{4}$ Profikomp Environmental Technologies Inc., Kühne Ede 7., Gödöllö 2100, Hungary

(e-mail:varga.zsolt@profikomp.hu,alexa@profikomp.hu)

${ }^{*}$ Corresponding author

e-mail: uveges.zsuzsanna@mgi.naik.hu; phone: +36-70-313-7480

(Received $6^{\text {th }}$ Apr 2020; accepted $14^{\text {th }}$ Aug 2020)

\begin{abstract}
Biogas production can support waste management efficiently - such an integrated system may reflect the approaches of a circular economic strategy. Our purpose was to assist in this task through the quantification of the methane potential of several substrates in Hungary, and by an investigation of the correlation between methane potential values and other biological-chemical parameters. The experimental substrates $(\mathrm{n}=10)$ were wastes and agricultural byproducts. Mesophilic anaerobic fermentation tests were carried out with the instrument AMPTS II in three parallel runs. Substrate from municipal solid waste was excluded, thus the number of parallel tests was nine. In addition, the following properties were assessed $(\mathrm{n}=3)$ : organic matter, total solid content, volatile solid content (calculated), $\mathrm{pH}, \mathrm{C} / \mathrm{N}$ ratio, and respiration intensity. The methane potential values of the investigated substrates confirmed that Hungary has considerable potential for biogas production. Significant correlation was detected between methane potential (an anaerobic process) and respiration intensity (an aerobic process): the correlation was linear at $R^{2}=0.9899$. This phenomenon is very important and the finding is innovative although further research is required.
\end{abstract}

Keywords: aerobic degradation, anaerobic degradation, biogas, manure, municipal solid waste

\section{Introduction}

Environmental pollution, the uncertainty surrounding energy supplies, human and animal hygiene, and promoting the security of the food industry require complex and sustainable solutions that include treating and utilizing wastes and byproducts. Treating such materials using anaerobic fermentation has two main advantages: biogas is suitable for producing electricity and thermal power, and the composted digestate as a stable product has auspicious agronomic properties. Accordingly, the proportion of renewable energy that is produced and used can be increased, while the composted digestate is suitable for substituting synthetic fertilizers in agricultural practice, and the effective treatment of wastes and their byproducts is thereby supported.

Research on anaerobic fermentation technology is going through a revolution. The selection of suitable input materials, the preparation methods for substrates, the adjustment of circumstances during the sensitive process - all of these aspects require further scientific research before biogas plants can be operated effectively (Angelidaki 
and Ahring, 1992, 1993, 1994; Cheng and Zhong, 2014; Tabatabaei et al., 2018). In this paper the results of methane potential tests are presented. One of our purposes was to characterize the potential substrates in Hungary for biogas production and contribute to the establishment of a scientific database related to the Hungarian conditions. It is important to know the properties of the substrates found in Hungary, because the country possess's significant unutilized potential in biogas production. An additional purpose was to identify the correlation between methane potential (MP) and respiration intensity $\left(\mathrm{AT}_{4}\right)$ value of a substrate. The goal of it was to find a faster method for determination of suitability of potential substrate materials for biogas production. Carbon-to-Nitrogen ratio $(\mathrm{C} / \mathrm{N})$ is not proper in all of the cases (for example in the case of heterogeneous materials). Traditional MP tests need one month, however respiration intensity tests can be performed in 4-5 days.

\section{Present results of methane potential tests}

In the last few years, a number of studies about biomethane potential (BMP) tests have been carried out to demonstrate biodigestability, methane yield, reaction-rate kinetics, the extent of anaerobic activity, the influence of pretreatment, and the effects of mixing different viscosities (André et al., 2016; Wang et al., 2017a; Passos et al., 2017; Raj Paudel et al., 2017; Siddique et al., 2018). Many types of substrates, such as solid household waste, pulp and paper mill sludge, wastewater sludge, commercial foodwaste, livestock materials (manures) and agricultural byproducts, and plant residues have been investigated (Wang et al., 2012; Wei et al., 2015; Hidalgo and Martín-Marroquín, 2015; Pecorini et al., 2016; Ebner et al., 2016; Neshat et al., 2017). Pecorini and his colleagues (2016) also reported that BMP tests can contribute to characterizing and evaluating the optimal performance of a full-scale anaerobic digestion (AD) process.

Li et al. (2015) reported the laboratory scale methane potential (MP) tests of pig-, dairy-, cattle-, and rabbit manure. Based on the volatile solid (VS) (referred to dry matter; d.m.) and $\mathrm{pH}$ values of the substrates, these samples may be suitable for biogas production, although their $\mathrm{C} / \mathrm{N}$ ratio and cellulose and lignin contents were not found to be adequate. Their analysis confirms that manures from different types of livestock may have very different properties, leading to variable performance in biogas production. During BMP tests different organic loading rates (OLR) were also investigated: 8, 16, 32, and $64 \mathrm{~g} \mathrm{VS/l}$. Results show that the maximum point of the methane potential curve was reported increasingly later in time, and cumulative methane potential decreased due to the increasing OLR. A further important result is the observation of a decrease in the degradation of organic material while OLR increases. De la Rubia et al. (2009) explained this phenomenon by claiming that high substrate concentration can lead to the inhibitory effects of ammonium-nitrogen. Another possible reason is the decrease in inoculum-tosubstrate ratio. Dairy manure produced the lowest amount of methane because of its fibre content. Research by Wu et al. (2017) confirmed the results of Li and his colleagues: swine manure contains cellulose and hemicellulose in high proportions, which compounds have a low hydrolysis rate, therefore their biodegradability is also low. Thermal pretreatment of carbohydrates increases methane production: without pretreatment the MP of swine manure is $201.9 \mathrm{ml} \mathrm{CH} / \mathrm{gVS}$; however, three-day thermal treatment may increase MP by $39.5 \%$.

Hardly biodegradable carbohydrates are present in significant proportions also in the organic fraction of municipal solid waste (OFMSW). OFMSW investigated by Ventorino et al. (2018) contained 30\% cellulose, $21 \%$ hemicellulose, $15 \%$ starch, $12 \%$ 
pectin and 20\% lignin. Ventorino performed medium-scale BMP tests (digesters were 1001 in capacity). According to their results, mechanical pretreatment efficiently increases biogas production. Krause et al. (2018) sorted an OFMSW fraction into its components and analyzed them separately, creating opposing results: in the case of certain carbohydrates, decreasing the size of pieces did not have a significant effect on MP. An important difference between the two types of examination is the method: Ventorino (2018) used dry fermentation, while Krause (2018) used wet fermentation. Dry fermentation is recommended if the dry matter content of the substrate is over $15 \%$ (Li et al., 2011; Ge et al., 2016; Chiumenti et al., 2018). However, this technology is not in practice routinely used. Riya et al. (2018) performed dry fermentation tests using 201 volume and a semi-batch run. He found that the operation of the reactor can be stable if total solid (TS) content is between $18-27 \%$.

However, it should be mentioned that the determination of methane potential is lacking with regard to the standardization of protocols (André et al., 2018). The values obtained by different laboratory procedures represent the methane potential stated in the literature that is used to dimension the units, thus sometimes resulting in under- or oversizing. An interlaboratory assay in France involving eleven laboratories showed that interlaboratory reproducibility had a coefficient of variation (CV) of $20 \%$ and an interlaboratory repeatability with a $\mathrm{CV}$ of $10 \%$ for a given substrate, although different protocols were used in the laboratories (Cresson et al., 2015). For any given protocol and substrates, interlaboratory reproducibility had a CV of $17 \%$, and a CV of $5 \%$ for intralaboratory reproducibility. In addition, anaerobic fermentation is an extremely complex process which is influenced significantly by biological-chemical factors, living and non-living agents, and the interactions between these (Ebner et al., 2016; Tsapekos et al., 2017). The more influential physical-chemical parameters are temperature, $\mathrm{pH}$, $\mathrm{C} / \mathrm{N}$ ratio, OLR, alkalinity, and the concentration of volatile fatty acids (VFAs) (Tufaner and Avsar, 2016; Koch et al., 2017; Ventorino et al., 2018). Nevertheless, a new European interlaboratory assay is taking place and should soon provide new conclusions in this aspect (Holliger et al., 2016).

\section{Alternative parameters for characterization instead of BMP}

Although BMP tests can be carried out very simply by using AMPTSII (Automatic Methane Potential Test System), this process takes at least 3-4 weeks, thus it would be practical and useful to be able to characterize potential substrates with analytical methods which take less time. Moreover, if such an analysis can be standardized, the reproducibility and reliability of results could be improved.

According to Wang et al. (2017b), the determination of the available carbon to nitrogen ratio $(\mathrm{AC} / \mathrm{N})$ may be an alternative way to appraise the suitability of potential substrates for biogas production. This procedure is particularly efficient in the case of substrates which contain slowly biodegradable compounds. However, all types of manure and MSW contain such components to some degree.

NIR spectroscopy (Near Infrared Reflectance Spectroscopy) can also be suitable for determining MP quickly and precisely (Triolo et al., 2014). NIRS is a non-destructive, real-time measurement which has also been used in biofuel technology over the last decade. In addition, there are a few studies regarding the application of NIRS in the estimation of methane potential - these are based on the following substrates: MSW; MSW mixed with agroindustrial wastes; and meadow grass (Lesteur et al., 2011; Raju et al., 2011; Doublet et al., 2013), respectively. The goal of Triolo and his colleagues was 
to set up a robust model for predicting BMP based on NIR spectra. Their study is satisfactory and the related model can be used for the estimation of BMP. However, it should be mentioned that NIRS requires specific user knowledge, and a reference spectra database must be set up for calibration.

Standardized respiration intensity can be a further alternative for appraising MP. One suitable piece of equipment for performing such measurement is the so-called OxiTop ${ }^{\circ}$. Its scope is limited to determining the biodegradable organic content of mechanicallybiologically treated wastes (there are a lot of cases when traditional analytical methods total organic carbon, dissolved organic carbon, loss on ignition - are not suitable for determining this).

\section{Tests using OxiTop ${ }^{\circledR}$}

Standardized German and Austrian methods for determining respiration activity $\left(\mathrm{AT}_{4}\right)$ are based on equipment made by Sapromat $\AA$. This technology is associated with several advantages (fluctuations in atmospheric pressure do not affect the measurements; oxygen is not a limiting factor; a great amount of data can be fixed; its operation is flexible), although the use of OxiTop ${ }^{\circledR}$ has become increasingly frequent over the last few years. The reason for this is the fact that OxiTop ${ }^{\circledR}$ is rather user-friendly and cheaper. It is, however, necessary to execute comparison tests in order to confirm the hypothesis that the two methods are equivalent. Binner et al. (2012) studied wastes $(n=169)$ using both methods to the determine statistical relationship between them. Results showed that the correlation was good: $\mathrm{R}^{2}=0.987$. The coefficient of determination was also appropriate in the case of low reaction wastes $\left(\mathrm{AT}_{4}<20 \mathrm{mg} \mathrm{O} / \mathrm{g} \mathrm{d.m}\right.$.): $\mathrm{R}^{2}=0.983$. This research confirms that Sapromat ${ }^{\circledR}$ can be substituted by OxiTop ${ }^{\circledR}$.

This is important for us, because our purpose was to find an appropriate method to prise the suitability of substrates for biogas production. $\mathrm{C} / \mathrm{N}$ ratio is not proper in all of the cases (for example in the case of heterogeneous materials). Traditional MP tests need one month, however respiration intensity tests can be carried out in 5 days. Further purpose was to characterize substrate materials in Hungary.

\section{Materials and methods}

\section{Experimental materials}

\section{Substrates}

The samples were different manures and wastes; their abbreviations are listed in Table 1 .

Table 1. Abbreviations of the substrates

\begin{tabular}{c|c}
\hline Name of the samples & Abbreviation \\
\hline Cattle manure with litter 1 & CMwL 1 \\
Cattle manure with litter 2 & CMwL 2 \\
Liquid cattle manure with straw & LCMwS \\
Swine manure & SM \\
Spent mushroom compost & SMC \\
Cattle manure fresh-compost & CMC \\
Liquid cattle manure with shredded straw & LCMwSS \\
Liquid swine manure with straw & LSMwS \\
Separately collected green waste & GW \\
\hline
\end{tabular}


CMwL1 and CMwL2 are littered manures, while LCMwS and LCMwSS are liquid cattle manures. The difference between them is the method of pretreatment. We mixed these liquid manure samples with straw, but in the case of LCMwSS the straw was shredded into pieces of $2 \mathrm{~cm}$ size. SMC refers to spent mushroom. CMC is fresh cattle manure compost. SM is swine manure, while LSMwS is liquid swine manure with straw. Municipal solid waste (MSW) was treated using mechanical-biological methods. We investigated the fraction which is smaller than $25 \mathrm{~mm}$. Green waste $(\mathrm{GW})$ was supplied by a regional waste collection company. In the case of liquid manures, tests were executed after mixing them with straw in proportions of $1: 1$ by weight. The biodegradability of straw was not increased in advance (for example, using aerobic methods) to enhance hydrolysis. Straw was only shredded in the case of LCMwSS.

\section{Inoculum}

We obtained the inoculum from the mesophilic reactor of an operating plant in Hungary. The substrates of this plant are agricultural materials (animal manure and plant residue) and industrial food byproducts.

\section{Experimental methods}

\section{BMP tests with AMPTSII}

The anaerobic digestion study was carried out in AMPTS II, produced by Bioprocess Control AB. Comparison tests were performed using AMPTS II for determining BMP. Results confirmed the reliability of the method (Kleinheinz and Hernandez, 2016).

Before the tests, BMP reactors were purged with high purity nitrogen for three minutes to remove oxygen from the reactor head-space. The exact weight of substrates and inoculum was calculated by software based on the volatile solid content (VS) and the inoculum-to-substrate ratio (I/S). The latter was always $2: 1$. The total volume of substrate and inoculum in the reactors was always $400 \mathrm{ml}$, therefore the volume of the gas that was produced was $200 \mathrm{ml}$.

Blanks and positive blanks (references) were measured in every sequence in parallels of 3-3, thus we could measure only three different substrates (also arrayed in 3-3 parallels) in one sequence. In the case of blank measuring, only inoculum was entered into the reactors after weighing. In the case of positive blanks, we used microcrystalline cellulose, a product made by Molar Chemicals Kft. The positive blank was used as a reference with regard to identifying the biologically activity of the inoculum.

The length of time for one sequence was 20-30 days. Tests were stopped if the volume of methane produced in one day was less than $20 \mathrm{ml}$.

\section{Further measurements}

Before starting the tests it was necessary to determine the total solid (TS) and the organic matter $(\mathrm{OM})$ content of the substrates and the inoculum; furthermore, to calculate VS content. The calculation of VS was accomplished according to Eq.1.

$$
\operatorname{VS}(\%)=\left(\mathrm{m}_{\text {dried }}-\mathrm{m}_{\text {burned }}\right) / \mathrm{m}_{\text {wet }}
$$

These data were necessary for determining the exact weight of the substrates and the inoculum to be put into the reactors. Total solid measurement was done based on the standard MSZ EN 13040:2008. Measurements of organic matter were based on the 
method of loss on ignition (LOI) (MSZ EN 15935:2013). Further analytical measurements were carried out: $\mathrm{C} / \mathrm{N}$ ratio, respiration intensity, and $\mathrm{pH}$. Measurements of carbon and nitrogen content were performed using Elementar Vario Macro, the standard for which was MSZ EN ISO 16948:2015. Respiration intensity values were determined by using OXITOP $®$. Originally, the procedure was standardized to measure the biological stability of wastes, although it has been confirmed that OXITOP ${ }^{\circledR}$ can be efficiently and reliably used for another purposes (Binner et al., 2012; Malinska, 2016). The temperature at which measurement was taken was $20^{\circ} \mathrm{C}$, and the duration of the tests was seven days (accordingly, the abbreviation for this measurement in the following parts of the paper is $\mathrm{AT}_{7}$ ). $\mathrm{pH}$ was measured according to the standard MSZ EN 13037:2012. Every analytical measurement was carried out in three replications.

\section{Statistical methods}

The statistical analyses were performed using PAST3 statistical program version 1.0.0.0. Three independent replicates were used for each measurement. One exception is the BMP measurements of municipal solid waste $(n=9)$. We did polynomial regression calculation on BMP curves. We accomplished normality tests and Levene's tests on methane potential, respiration intensity, carbon-to-nitrogen ratio and organic matter data. Valid normality and homogeneity of variance are minimum assumptions to doing ANOVA analysis on data. ANOVA analysis could not be used because of the violation of the assumptions, therefore non-parametric Kruskal-Wallis tests were accomplished on data.

Relationship between the four mentioned parameters (MP, $\mathrm{AT}_{7}, \mathrm{C} / \mathrm{N}, \mathrm{OM}$ ) was checked by cluster analysis.

\section{Results}

TS, VS, OM, C/N ratio, $\mathrm{pH}$ and respiration intensity results for the substrates can be seen in Table 2. The values represented are the averages of three replicate measurements in every case. VS is a calculated parameter (Eq.1). Relative deviation values (SD\%) are represented in parenthesis for every substrate and every measurement. Relative deviation value of LSMwS in the case of TS measurements is outstanding. Probably the reason of that is the mistake of sample weighing (differences in the straw content). Relative deviation value of MSW in case of the $\mathrm{pH}$ measurements is also higher by an order of magnitude than the other $\mathrm{pH}$ values. The reason is the characteristic of MSW sample - MSW is very heterogenous so the number of replicates was not enough in this case.

From the perspective of anaerobic digestion, the $\mathrm{pH}$ values for substrates of agricultural origin were neutral or weakly alkaline, therefore adjustment of $\mathrm{pH}$ was not necessary. In the case of MSW, $\mathrm{pH}$ was low (5.44; SD\%=10.4\%), but we did not add sodium-hydroxide because $\mathrm{Na}^{+}$ions in high concentration may inhibit the process of anaerobic fermentation. The $\mathrm{C} / \mathrm{N}$ ratio was outside the acceptable range (20-30) in the case of four substrates: SMC and CMC had a slightly lower value (13.9 and 11.6, respectively), while LCMwS and LCMwSS substrates had a higher $\mathrm{C} / \mathrm{N}$ ratio than optimal (34.1 and 73.2, respectively). BMP and respiration intensity $\left(\mathrm{AT}_{7}\right)$ values can be seen in Table 3. The number of parallel measurements was also three. In the case of BMP measurements of MSW the number of replicates was 9 because of its heterogenity. 
Table 2. Characterisation of the substrates

\begin{tabular}{|c|c|c|c|c|c|}
\hline & $\begin{array}{l}\text { TS [\%] } \\
(\mathrm{SD} \%)\end{array}$ & $\begin{array}{c}\text { OM [\%] } \\
(\mathrm{SD} \%)\end{array}$ & VS [\%] & $\begin{array}{c}\text { C/N ratio } \\
(\mathrm{SD} \%)\end{array}$ & $\begin{array}{c}\text { pH } \\
(\mathrm{SD} \%)\end{array}$ \\
\hline Inoculum $(n=3)$ & $5.9(5.2 \%)$ & $80.5(1.3 \%)$ & 4.7 & - & $7.90(0.8 \%)$ \\
\hline $\begin{array}{c}\text { CMwL } 1 \\
(n=3)\end{array}$ & $\begin{array}{l}18.2 \\
(4.5)\end{array}$ & $\begin{array}{c}87.5 \\
(0.9 \%)\end{array}$ & 15.9 & $\begin{array}{c}20.7 \\
(0.9 \% / 1.8 \%)\end{array}$ & $\begin{array}{c}8.46 \\
(0.5 \%)\end{array}$ \\
\hline $\begin{array}{c}\text { CMwL } 2 \\
(n=3)\end{array}$ & $\begin{array}{c}14.7 \\
(3.5 \%)\end{array}$ & $\begin{array}{c}84.2 \\
(0.9 \%)\end{array}$ & 12.4 & $\begin{array}{c}23.9 \\
(0.3 \% / 6 \%)\end{array}$ & $\begin{array}{c}8.37 \\
(1.4 \%)\end{array}$ \\
\hline $\begin{array}{c}\mathrm{LCMwS} \\
(\mathrm{n}=3)\end{array}$ & $\begin{array}{c}7.2 \\
(12.3 \%)\end{array}$ & $\begin{array}{c}89.6 \\
(1.3 \%)\end{array}$ & 6.5 & $\begin{array}{c}34.1 \\
(1.8 \% / 10.5 \%)\end{array}$ & $\begin{array}{c}7.98 \\
(1.1 \%)\end{array}$ \\
\hline $\begin{array}{c}\mathrm{SM} \\
(\mathrm{n}=3)\end{array}$ & $\begin{array}{c}24.8 \\
(3.9 \%)\end{array}$ & $\begin{array}{c}88.1 \\
(2.8 \%)\end{array}$ & 21.9 & $\begin{array}{c}22.3 \\
(0.3 \% / 6.9 \%)\end{array}$ & $\begin{array}{c}8.16 \\
(0.7 \%)\end{array}$ \\
\hline $\begin{array}{l}\text { SMC } \\
(n=3)\end{array}$ & $\begin{array}{c}34.6 \\
(2.0 \%)\end{array}$ & $\begin{array}{c}53.5 \\
(4.0 \%)\end{array}$ & 18.5 & $\begin{array}{c}13.9 \\
(5.4 \% / 1.9 \%)\end{array}$ & $\begin{array}{c}7.04 \\
(0.5 \%)\end{array}$ \\
\hline $\begin{array}{l}\text { CMC } \\
(\mathrm{n}=3)\end{array}$ & $\begin{array}{c}38.1 \\
(19.8 \%)\end{array}$ & $\begin{array}{c}59.9 \\
(29.4 \%)\end{array}$ & 22.0 & $\begin{array}{c}11.6 \\
(3.2 \% / 2.3 \%)\end{array}$ & $\begin{array}{c}7.17 \\
(0.5 \%)\end{array}$ \\
\hline $\begin{array}{l}\text { LCMwSS } \\
\quad(\mathrm{n}=3)\end{array}$ & $\begin{array}{c}5.6 \\
(9.9 \%)\end{array}$ & $\begin{array}{c}87.5 \\
(4.8 \%)\end{array}$ & 4.9 & $\begin{array}{c}73.2 \\
(2.1 \% / 10.5 \%)\end{array}$ & $\begin{array}{c}8.00 \\
(0.7 \%)\end{array}$ \\
\hline $\begin{array}{l}\text { LSMwS } \\
(n=3)\end{array}$ & $\begin{array}{c}18.5 \\
(53.3 \%)\end{array}$ & $\begin{array}{c}82.0 \\
(0.6 \%)\end{array}$ & 15.2 & $\begin{array}{c}21.3 \\
(0.8 \% / 10.6 \%)\end{array}$ & $\begin{array}{c}6.72 \\
(1.7 \%)\end{array}$ \\
\hline $\begin{array}{c}\text { GW } \\
(\mathrm{n}=3)\end{array}$ & $\begin{array}{c}45.4 \\
(6.1 \%)\end{array}$ & $\begin{array}{c}56.9 \\
(0.9 \%)\end{array}$ & 25.8 & $\begin{array}{c}18.1 \\
(2.2 \% / 1.4 \%)\end{array}$ & $\begin{array}{c}7.22 \\
(0.9 \%)\end{array}$ \\
\hline $\begin{array}{l}\text { MSW } \\
(\mathrm{n}=3)\end{array}$ & $\begin{array}{c}47.54 \\
(7.0 \%)\end{array}$ & $\begin{array}{c}59.57 \\
(3.3 \%)\end{array}$ & 28.3 & $\begin{array}{c}23.0 \\
(3.7 \% / 2.0 \%)\end{array}$ & $\begin{array}{c}5.44 \\
(10.4 \%)\end{array}$ \\
\hline
\end{tabular}

Table 3. Average BMP and respiration intensity values of the substrates. Relative deviation values $(S D \%)$ are represented in parenthesis

\begin{tabular}{c|c|c|c}
\hline Abbreviation & $\begin{array}{c}\text { Average BMP [Nml/gVS] } \\
\text { (SD\%) }\end{array}$ & $\begin{array}{c}\text { Duration of AD } \\
\text { [days] }\end{array}$ & $\begin{array}{c}\text { AT }_{7}\left[\mathbf{m g ~ O} \mathbf{O}_{2} / \mathbf{g ~ d . m . ]}\right. \\
\text { (SD\%) }\end{array}$ \\
\hline CMwL 1 (n=3) & $173.0(3.1 \%)$ & 29 & $58(6.6 \%)$ \\
CMwL 2 (n=3) & $149.4(15.4 \%)$ & 29 & $41(9.9 \%)$ \\
LCMwS (n=3) & $370.1(6.4 \%)$ & 29 & $159(2.8 \%)$ \\
SM (n=3) & $136.2(2.9 \%)$ & 29 & $46(5.4 \%)$ \\
SMC (n=3) & $48.4(5.4 \%)$ & 19 & $9(8.7 \%)$ \\
CMC (n=3) & $135.9(30.2 \%)$ & 19 & $40(22.1 \%)$ \\
LCMwSS (n=3) & $250.06(3.3 \%)$ & 19 & $98(4.8 \%)$ \\
LSMwS (n=3) & $156.3(14.4 \%)$ & 20 & $50(9.2 \%)$ \\
GW (n=3) & $72.81(17.0 \%)$ & 20 & $7(12.6 \%)$ \\
MSW & $325.71(16.7 \% . n=9)$ & 19 & $137(3.7 \% . n=3)$ \\
\hline
\end{tabular}

AMPTS II equipment saves data in continuously cumulated form, although separately, on a daily basis. Accordingly, we can characterize every single day according to the amount of methane that was produced and the differences in the three parallel measurements. The standard deviation of the blank measurements were between 1.3 - $14.87 \%$ in every measuring sequence. Positive blank measurements also confirmed the microbiological activity of the inoculum in every measuring sequence $(0.2-10.6 \%)$. 
Based on the results concerning respiration intensity, SMC and GW substrates contained biologically degradable organic matter in low amounts (9 and $7 \mathrm{mg}$ $\mathrm{O}_{2} / \mathrm{g}$ d.m., respectively), and their average BMP values are in line with this finding. LCMwS is outstanding from the point of view of respiration intensity $(159 \mathrm{mg}$ $\mathrm{O}_{2} / \mathrm{g}$ d.m.); however, MSW and LCMwSS also showed high activity (137 and $98 \mathrm{mg}$ $\mathrm{O}_{2} / \mathrm{g}$ d.m., respectively). CMC and CMwL2 substrates (which contained nutrients hardly available to microorganisms in anaerobic digestion processes based on the shape of BMP curves (Fig. 1), standardized curves (Fig. 2), and gradient values (Table 4)) showed medium respiration intensity (40 $\mathrm{mg} \mathrm{O} / \mathrm{g} \mathrm{d.m.} \mathrm{(22.1 \% )} \mathrm{and} 41 \mathrm{mg} \mathrm{O} / \mathrm{g} \mathrm{d.m.}$ (9.9\%), respectively). Further results concerning the respiration intensity of all of the substrates and their standard deviations can be seen in Table 3. Relative deviations of $\mathrm{CMC}$ in the case of $\mathrm{BMP}$ and $\mathrm{AT}_{7}$ measurements (30.2\% and $22.1 \%$ respectively) are outstanding. CMC sample was a fresh compost, so the reason probably is the heterogenity.

The average methane potential curves of the substrates can be seen in Fig. 1 .

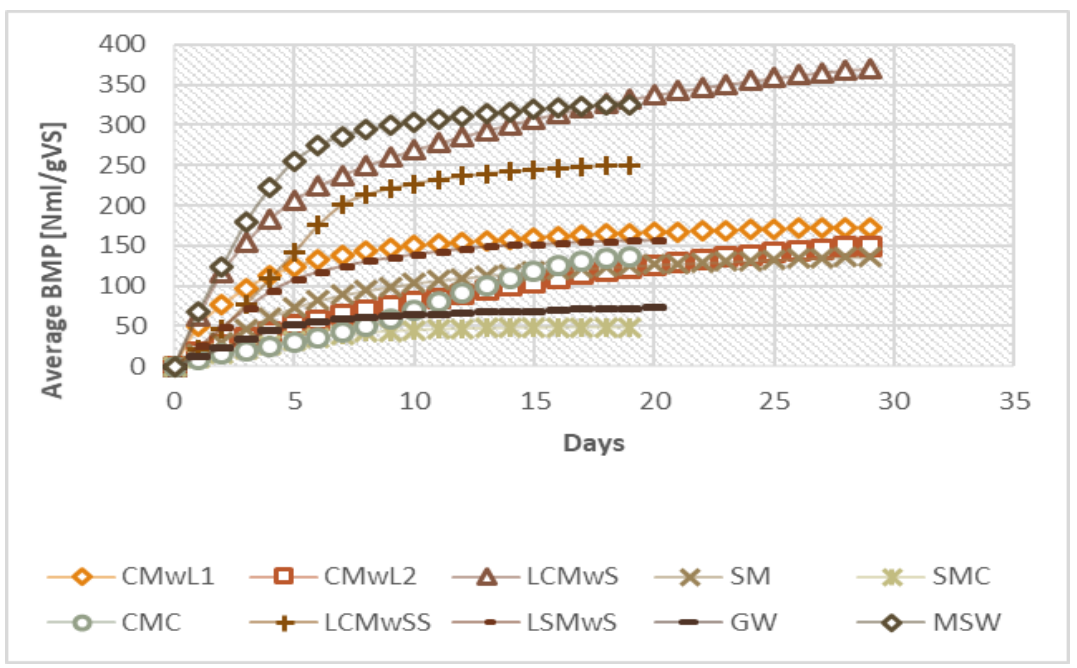

Figure 1. BMP curves of the substrates

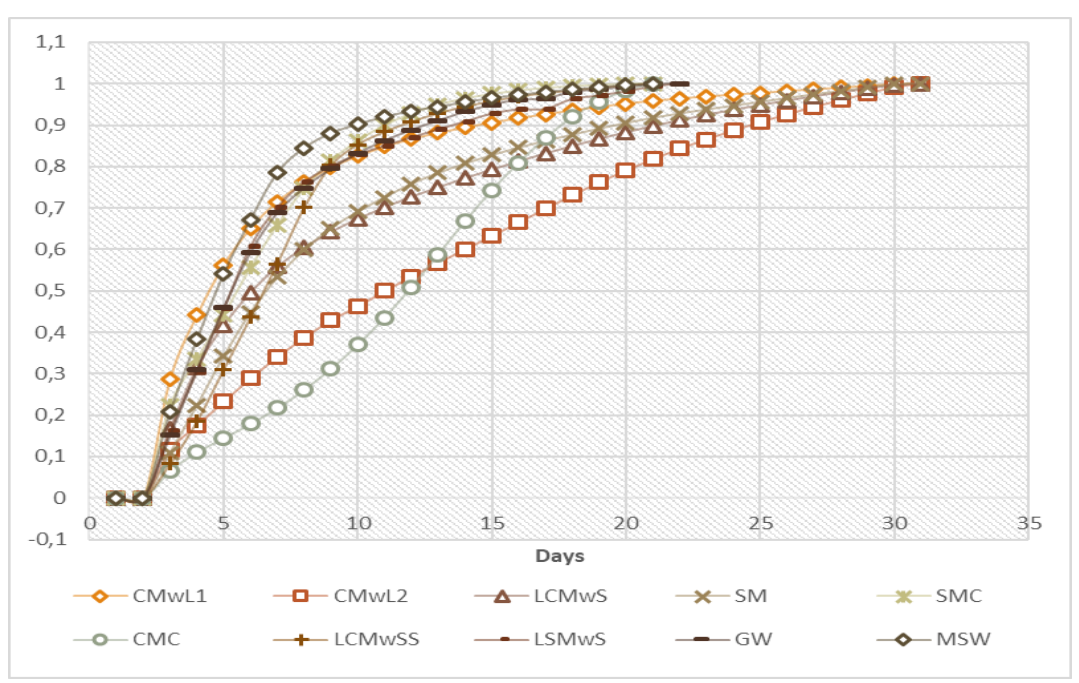

Figure 2. Standardized methane potential curves 
Table 4. Gradiation values of the initial phase (first 5 days) of MP curves

\begin{tabular}{c|c|c}
\hline & $\mathbf{y}$ & $\mathbf{R}^{\mathbf{2}}$ \\
\hline CMwL1 & 23.661 & 0.9299 \\
CMwL2 & 9.7244 & 0.9754 \\
LCMwS & 41.018 & 0.9650 \\
SM & 15.386 & 0.9997 \\
SMC & 6.0845 & 0.9778 \\
CMC & 5.6638 & 0.0983 \\
LCMwSS & 31.116 & 0.9983 \\
LSMwS & 21.942 & 0.9940 \\
GW & 10.984 & 0.9997 \\
MSW & 51.306 & 0.9865 \\
\hline
\end{tabular}

The shape of the BMP curve for substrate CMwL1 refers to the right conditions for anaerobic digestion. Based on the shape of the BMP curve of substrate CMwL2 (it has a moderate gradient), it is clear that the organic matter content is hardly available to microorganisms. Considering the results of the previous analytical measurements, there is significant difference between the two substrates in terms of $\mathrm{AT}_{7}$. These seven-day and aerobic tests also showed the low availability of nutrients for microorganisms in the substrate-inoculum mixes (Table 3). In the case of LCMwSS, the high $\mathrm{C} / \mathrm{N}$ value (73.2) indicated in forward inhibitor processes during $\mathrm{AD}$, which assumption is confirmed by the shape of the BMP curve. The results for the CMC substrate are also expressed in average values, which is misleading: BMP (Table 3), respiration intensity (Table 3) and OM content (Table 2) results for CMC are associated with a notable standard deviation. In the case of MP tests, two measurements of the three replications showed the following: gas production started on the fifth day, and at the end of the test the final and cumulated methane yields showed more than 30\% standard deviation relative to each other. Results of previous measurements of SMC substrate (low OM content $(53.5 \%)$, $\mathrm{C} / \mathrm{N}$ ratio (13.9) and respiration intensity ( $\left.40 \mathrm{mg} \mathrm{O}_{2} / \mathrm{g} \mathrm{d.w.)}\right)$ also indicated inhibition of microbial gas production. MSW is a strongly heterogeneous substrate, although the actual results also confirm its significant biodegradable material content. The average BMP of the nine MSW measurements (325.71 Nml/gVS, SD=16.7\%, $\mathrm{n}=9$ ) is in line with finding in the literature (Jokela et al., 2005; Liu et al., 2008; Pecorini et al., 2016; Krause et al., 2018; Ventorino et al., 2018).

Standardized curves were made from the standardized BMP values (calculation was based on the average values), and shown in Figure 2. In this way, the quality of degradation processes in the single reactors can be compared easily.

It can also be seen that CMC and CMwL2 substrates contained only weakly available nutrients (Fig. 2). The initial gradient of the curves (Table 4) indicates the previous phenomenon in numbers. Based on the standardization, there was no significant difference in the quality of microbial degradation processes between the nine parallel measurements of MSW (Fig. 3). Final and cumulated methane production varied between $228.86-385.57 \mathrm{Nml} / \mathrm{gVS}(\mathrm{SD} \%=16.7 \%)$ because of the quantity of added $\mathrm{OM}$; however, biochemical processes continued very similarly, despite the heterogeneity of the MSW substrate. 


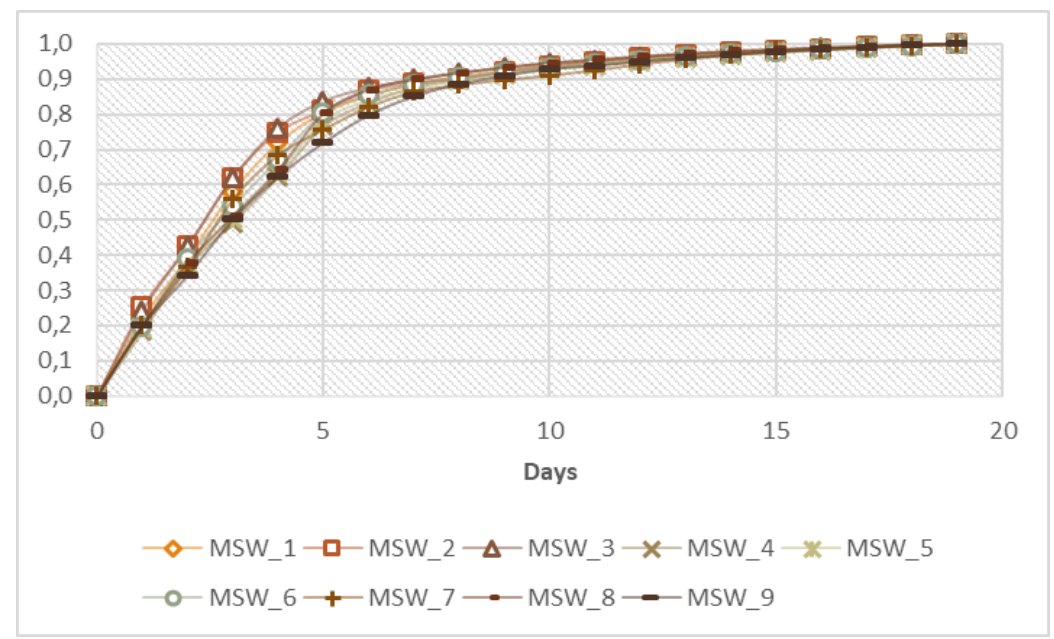

Figure 3. Standardized curves of the nine parallel measurements of MSW

The gradients of the initial five days of methane potential curves, and also the accuracy values for linear trend-lines can be seen in Table 4. The initial intensity of methane production shows the availability of organic matter in the substrate. Based on this conception, the $\mathrm{OM}$ content of CMC and SMC substrates was hardly available, although in case of $\mathrm{CMC}$, after the first step of $\mathrm{AD}$ (hydrolysis), aerobic and anaerobic

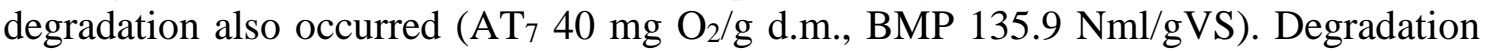

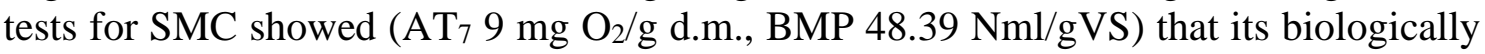
degradable organic matter content was minimal. Total organic matter content was measured with the 'loss on ignition' method; the result was also low: $53.5 \%$.

Very important experience during our experiments is the correlation between BMP and $\mathrm{AT}_{7}$ measurement. Respiration intensity measurement is based on aerobic biochemical processes, so the composition of the microbial consortium is different than under anaerobic conditions. However, data from these measurements (Table 3) showed strong correlation with BMP results from anaerobic digestion tests (Table 3). The correlation between the two kinds of data can be seen in Fig. 4. The quality markers of the linear correlation between the two parameters are: $\mathrm{r}=0.9955, \mathrm{R}^{2}=0.9911, \mathrm{t}=29.81$, $\mathrm{p}=1.7372 \mathrm{E}-09$, permutation $\mathrm{p}=0.0001$. The results of these tests confirm our hypothesis: previous respiration intensity tests of potential substrate materials indicate their suitability for biogas production. This is very useful in practice because BMP tests are very time consuming. Performing respiration intensity tests is more time-efficient.

\section{Statistical analyses}

The first step of the statistical analysis involved doing polynomial regression fittings (second, third and fourth order) on BMP curves. According to the qualitative parameters different orders were fitted for the certain curves. Second-order regression was applied in the following three cases (Table 5): $\mathrm{CMwL} 2, \mathrm{SMC}$, and CMC. Third-order regression was applied in the case of SM, LSMwS, and GW, and fourth-order in the case of CMwL1, LCMwS, LCMwSS, and MSW.

Normality tests were carried out on BMP, respiration intensity, $\mathrm{C} / \mathrm{N}$ ratio, and $\mathrm{OM}$ content results (Tables 6 and 7). Data of $\mathrm{AT}_{7}$ and $\mathrm{C} / \mathrm{N}$ ratio measurements were wellmodeled by normal distribution in case of all substrates. 


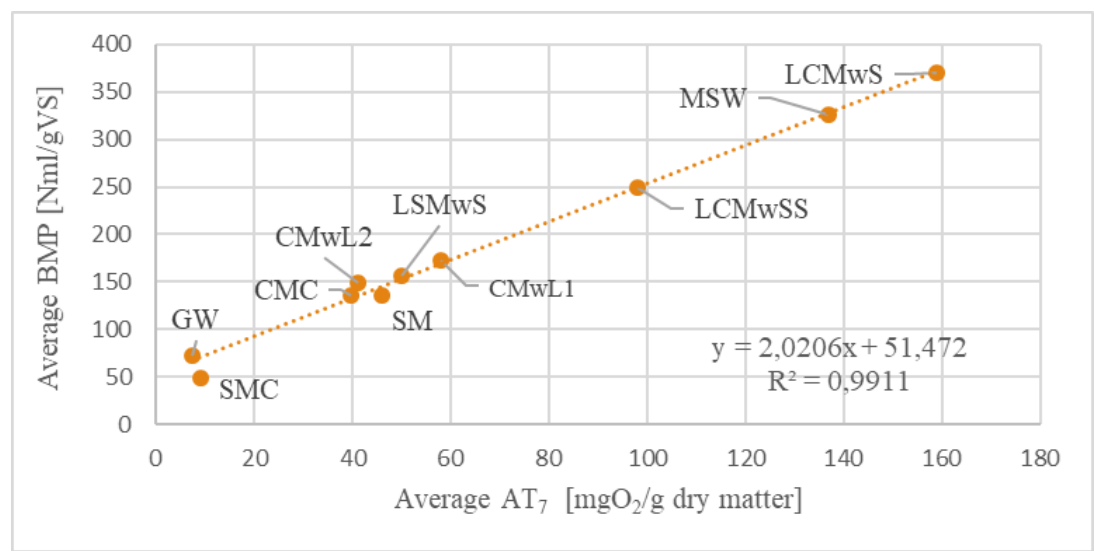

Figure 4. Relationship between respiration intensity and BMP results

Table 5. Data of polynomial regression tests accomplished on the average BMP curves

\begin{tabular}{|c|c|c|c|c|c|c|c|c|c|c|c|}
\hline \multirow{3}{*}{ Samples } & \multirow{2}{*}{\multicolumn{2}{|c|}{\begin{tabular}{|c|}
$\begin{array}{c}\text { Linear regression } \\
\text { of the initial } \\
\text { phase }\end{array}$ \\
\end{tabular}}} & \multicolumn{9}{|c|}{ POLYNOMIAL REGRESSION OF BMP CURVES } \\
\hline & & & \multicolumn{3}{|c|}{ Order 2} & \multicolumn{3}{|c|}{ Order 3} & \multicolumn{3}{|c|}{ Order 4} \\
\hline & $\mathbf{Y}$ & $\mathbf{R 2}$ & Akaike IC & $\mathbf{p}$ & $\mathbf{R 2}$ & Akaike IC & $\mathbf{p}$ & $\mathbf{R 2}$ & Akaike IC & $\mathbf{p}$ & $\mathbf{R 2}$ \\
\hline & 661 & 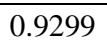 & 5762.60 & $4.48 \mathrm{E}$ & .8783 & 1707.00 & $6.81 \mathrm{E}+19$ & 0.9641 & 445.64 & $4.78 \mathrm{E}-25$ & 9908 \\
\hline CMwL2 & & & & $5.31 \mathrm{E}$ & 1 & & & 82 & 83 & 9 & \\
\hline LCMwS & 41.0180 & 50 & 9.50 & $4.80 \mathrm{E}$ & 674 & 3540.30 & 2.66 & 0.9862 & .47 & 3.66 & 77 \\
\hline SM & 15.3860 & 97 & 1496.00 & $4.09 \mathrm{E}$ & 634 & 174.88 & $3.89 \mathrm{I}$ & 0.9959 & 41.603 & 1.8 & \\
\hline SMC & 45 & 778 & 66 & $2.80 \mathrm{E}$ & 852 & 13.58 & 4.69 & 0.9986 & 576 & 3.1 & \\
\hline CMC & 5.6638 & 0.0983 & & $1.56 \mathrm{E}$ & 5 & & $3.03 \mathrm{E}$ & 0.9969 & 15 & 3.1 & \\
\hline LCMwSS & 31.1160 & 983 & 2000.80 & $2.93 \mathrm{E}$ & 851 & 1422.80 & $5.12 \mathrm{E}-16$ & 0.9895 & 649.38 & 3.2 & 52 \\
\hline LSMwS & 21.9420 & 0.999 & 1345.70 & $3.01 \mathrm{E}$ & 686 & 126.74 & $6.60 \mathrm{E}-22$ & 0.9972 & 26 & $2.52 \mathrm{E}-22$ & 0. \\
\hline GW & 10.9840 & 0.9997 & 402.80 & 7.54E- & 550 & 49.10 & $5.20 \mathrm{E}-20$ & 0.9953 & 36.344 & $5.68 \mathrm{E}-20$ & 0.9970 \\
\hline MSW & 51.3060 & 0.9865 & 3782.90 & $1.05 \mathrm{E}-11$ & 0.9489 & 703.03 & $2.02 \mathrm{E}-16$ & 0.9906 & 237.08 & $1.21 \mathrm{E}-18$ & 0.9969 \\
\hline
\end{tabular}

Table 6. Results of normality tests accomplished on BMP and respiration intensity data

\begin{tabular}{|c|c|c|c|c|c|c|c|c|c|c|c|}
\hline & & CMw & 2 & $\mathbf{S}$ & SM & SMC & CMC & LCMwSS & LSMwS & GW & MS \\
\hline \multirow{9}{*}{ BMP } & $\mathrm{N}$ & 3 & 3 & 3 & 3 & 3 & 3 & 3 & 3 & 3 & 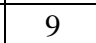 \\
\hline & Shapiro-W & 0 & & 789 & 0.7522 & 9087 & 0.7565 & & 66 & 9387 & \\
\hline & $\mathrm{p}$ (normal) & 482 & 694 & 50 & 0.0048 & 39 & 44 & & 05 & 2 & \\
\hline & Anderson-Darling A & 1073 & 057 & & 0.4850 & 936 & 94 & & 44 & & \\
\hline & $\mathrm{p}$ (normal) & 1122 & 0.5593 & 0.0773 & 0.0579 & 0.2910 & 0.0607 & 43 & 0.3138 & 0.3860 & 37 \\
\hline & $\mathrm{p}(\mathrm{M}$ & & & 656 & 0.0039 & & 53 & & & & \\
\hline & Jar & 79 & 126 & 0.5287 & 0.5312 & 0.4397 & 0.5311 & 67 & 4295 & 0.3975 & 0 \\
\hline & & & & 677 & 0.7667 & 027 & 0.7668 & & 68 & 0. & \\
\hline & & 0.1499 & 0.7693 & 0.0651 & 0.0050 & 0.4049 & 0.0144 & 0.8479 & 0.4428 & 0.5307 & 0.4282 \\
\hline & & \multicolumn{3}{|c|}{\begin{tabular}{|c|c|c|} 
CMwL 1 CMwL 2 LCMwS \\
\end{tabular}} & $\mathbf{S M}$ & SMC & CMC & LCMwSS & LSMwS & GW & MSW \\
\hline \multirow{9}{*}{ AT7 } & 10 & 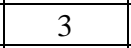 & & 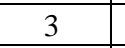 & 2 & 7 & 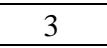 & & & 3 & \\
\hline & & & 893 & 9996 & 9548 & 8952 & 9892 & 24 & 79 & 0.8845 & 0.9669 \\
\hline & & & 024 & 0.9611 & 0.5906 & 0.3704 & 0.8011 & & 9125 & 0.3378 & 0.6503 \\
\hline & Anderson & 94 & 014 & 0.1900 & 0.2405 & 0.3094 & 0.2016 & 93 & .1918 & 0.3220 & 0.2267 \\
\hline & & 0.3269 & 766 & 0.6285 & 0.4469 & 0.2552 & 0.5760 & 14 & 0.6196 & 0.2296 & 0.4980 \\
\hline & $\mathrm{p}$ & 53 & 23 & 0.9594 & 0.5944 & 0.3678 & 0.8057 & 58 & 0.9133 & 0.3411 & 0.6632 \\
\hline & & 36 & 046 & 0.2822 & 0.3711 & 0.4557 & 0.3049 & 4350 & 0.2859 & 0.4672 & 0.3494 \\
\hline & & & 587 & 0.8684 & 0.8306 & 0.7962 & 0.8586 & 0.8045 & 0.8668 & 0.7917 & 0.8397 \\
\hline & p(Monte Carlo) & 0.4542 & 0.7999 & 0.9601 & 0.5871 & 0.3667 & 0.8004 & 0.4230 & 0.9097 & 0.3398 & 0.6526 \\
\hline
\end{tabular}


Table 7. Results of normality tests accomplished on C/N ratio and OM data

\begin{tabular}{|c|c|c|c|c|c|c|c|c|c|c|c|}
\hline & & CMwL 1 & \begin{tabular}{|c|} 
CMwL \\
2 \\
\end{tabular} & LCMwS & SM & SMC & CMC & LCMwSS & LSMwS & GW & MSW \\
\hline \multirow{9}{*}{$\mathrm{C} / \mathrm{N}$} & $\mathrm{N}$ & 3 & 3 & 3 & 3 & 3 & 3 & 3 & 3 & 3 & 3 \\
\hline & Shapiro-Wilk W & 1.0000 & 0.8789 & 0.8399 & 0.9181 & 0.8995 & 0.9643 & 0.8538 & 0.9927 & 0.9231 & 1.0000 \\
\hline & $\mathrm{p}$ (normal) & 1.0000 & 0.3212 & 0.2139 & 0.4458 & 0.3839 & 0.6369 & 0.2506 & 0.8362 & 0.4633 & 1.0000 \\
\hline & Anderson-Darling A & 0.1895 & 0.3287 & 0.3755 & 0.2826 & 0.3044 & 0.2296 & 0.3588 & 0.1977 & 0.2769 & 0.1895 \\
\hline & $\mathrm{p}$ (normal) & 0.6307 & 0.2171 & 0.1451 & 0.3184 & 0.2661 & 0.4867 & 0.1678 & 0.5927 & 0.3337 & 0.6307 \\
\hline & p(Monte Carlo) & 1.0000 & 0.3223 & 0.2032 & 0.4492 & 0.3832 & 0.6359 & 0.2447 & 0.8305 & 0.4627 & 1.0000 \\
\hline & Jarque-Bera JB & 0.2813 & 0.4728 & 0.5041 & 0.4274 & 0.4508 & 0.3541 & 0.4945 & 0.2974 & 0.4206 & 0.2813 \\
\hline & $\mathrm{p}$ (normal) & 0.8688 & 0.7895 & 0.7772 & 0.8076 & 0.7982 & 0.8377 & 0.7810 & 0.8618 & 0.8103 & 0.8688 \\
\hline & p(Monte Carlo) & 1.0000 & 0.3150 & 0.2141 & 0.4498 & 0.3811 & 0.6415 & 0.2497 & 0.8321 & 0.4554 & 1.0000 \\
\hline & & CMwL 1 & \begin{tabular}{|c|} 
CMwL \\
2 \\
\end{tabular} & LCMwS & SM & SMC & CMC & LCMwSS & LSMwS & GW & MSW \\
\hline \multirow{9}{*}{$\mathrm{OM}$} & $\mathrm{N}$ & 3 & 3 & 3 & 3 & 3 & 3 & 3 & 3 & 3 & 3 \\
\hline & Shapiro-Wilk W & 0.9985 & 0.7500 & 0.7500 & 0.8480 & 0.8300 & 0.8791 & 0.8547 & 0.9134 & 0.8196 & 0.9206 \\
\hline & $\mathrm{p}$ (normal) & 0.9265 & 0.0000 & 0.0000 & 0.2351 & 0.1884 & 0.3217 & 0.2530 & 0.4295 & 0.1623 & 0.4545 \\
\hline & Anderson-Darling A & 0.1911 & 0.4878 & 0.4878 & 0.3657 & 0.3876 & 0.3285 & 0.3577 & 0.2881 & 0.4003 & 0.2798 \\
\hline & $\mathrm{p}$ (normal) & 0.6228 & 0.0565 & 0.0565 & 0.1580 & 0.1305 & 0.2174 & 0.1694 & 0.3044 & 0.1191 & 0.3260 \\
\hline & $\mathrm{p}$ (Monte Carlo) & 0.9283 & 0.0001 & 0.0001 & 0.2404 & 0.1855 & 0.3246 & 0.2485 & 0.4255 & 0.1625 & 0.4549 \\
\hline & Jarque-Bera JB & 0.2846 & 0.5312 & 0.5312 & 0.4987 & 0.5100 & 0.4727 & 0.4938 & 0.4337 & 0.5154 & 0.4241 \\
\hline & $\mathrm{p}$ (normal) & 0.8674 & 0.7667 & 0.7667 & 0.7793 & 0.7749 & 0.7895 & 0.7812 & 0.8050 & 0.7728 & 0.8089 \\
\hline & p(Monte Carlo) & 0.9291 & 0.0001 & 0.0001 & 0.2361 & 0.1867 & 0.3210 & 0.2509 & 0.4379 & 0.1620 & 0.4563 \\
\hline
\end{tabular}

In the case of BMP results, data of three substrates were not well-modeled by normal distribution: SM, LCMwS and CMC. The non-compliance of the results of BMP for SM and $\mathrm{CMC}$ substrates may originate from the low number of parallel measurements. The CMC substrate was heterogeneous, as represented in the values for standard deviation.

In terms of $\mathrm{OM}$ content, another two substrates were not well-modeled by normal distribution: CMwL2, and LCMwS. This non-compliance may also be due to their heterogeneity and the low number of parallel measurements.

However homogeneity of variance is also an assumption of the ANOVA analysis, therefore we applied Levene's test to test the null-hypothesis that the variance is equal across groups. Both of normality and homogeneity of variance need to be valid on data for applying ANOVA analsyis. Calculations of Levene's tests were done from means and also from medians. (p) values calculated from means are the following: BMP 0.001029, $\mathrm{AT}_{7}$ 0.02819, C/N 0.0001289 and $\mathrm{OM} 3.24 \mathrm{E}-04$. (p) values calculated from medians are the following: BMP 0.3207, $\mathrm{AT}_{7} 0.194, \mathrm{C} / \mathrm{N} 0.5165$ and OM 0.3059. These results of Levene's tests mean a violation for the whole amount of data, therefore oneway ANOVA could not be applied for analyzing.

Calculated parameters of Kruskal-Wallis tests on measurement data are the following. For BMP: $\mathrm{H}(\mathrm{chi} 2)=25.9, \mathrm{Hc}($ tie corrected $)=25.9, \mathrm{p}=0.002119$. For $\mathrm{AT}_{7}$ : $\mathrm{H}(\mathrm{chi} 2)=27.51, \mathrm{Hc}(\mathrm{tie}$ corrected $)=27.51, \mathrm{p}=0.00115$. For $\mathrm{C} / \mathrm{N}: \mathrm{H}(\mathrm{chi} 2)=26.79, \mathrm{Hc}(\mathrm{tie}$ corrected $)=26.79, \mathrm{p}=0.001516$. For $\mathrm{OM}: \mathrm{H}(\mathrm{chi} 2)=25.84$, $\mathrm{Hc}($ tie corrected $)=25.87$, $\mathrm{p}=0.002145$. These result mean that there was a significant difference between sample medians in all of the measurements (BMP, $\left.\mathrm{AT}_{7}, \mathrm{C} / \mathrm{N}, \mathrm{OM}\right)$. 
Based on cluster analysis, there is direct correspondence between BMP and respiration intensity: the correlation is 0.9986 (Fig. 5).

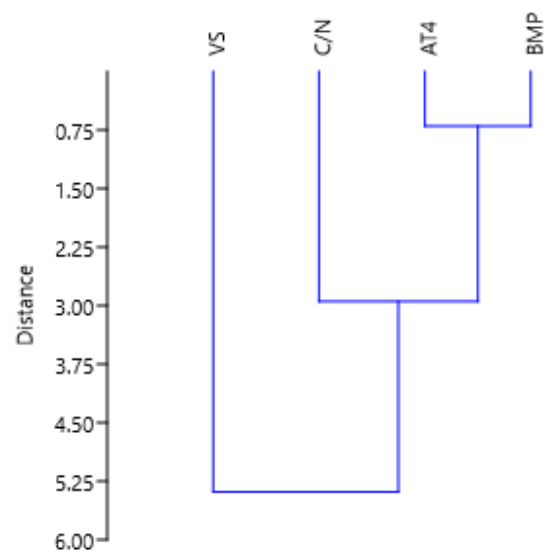

Figure 5. Cluster analysis between the investigated parameters

\section{Discussion}

Our results are in accordance with the results published in 2015 by Li et al. In these investigations, some substrates had an overly high or low $\mathrm{C} / \mathrm{N}$ ratio. In such cases, it is expedient to mix the substrate with material which has other chemical characteristics in order to meet the criteria for biochemical processes and effective reactor operating (for example straw). The liquid manure substrates represented in this study were mixed with straw or shredded straw (LCMwS, LCMwSS, LSMwS). The BMP value of liquid manure mixed with previously shredded straw was lower than the same liquid manure mixed with straw (without shredding) (Table 3). However this result are in contrast with general findings in the literature (Neshat et al., 2017; Raj Paudel et al., 2017) concerning the effects of mechanical pretreatment. Probably the degree of shredding was small in the case of our experiment.

Fiber-characterised compounds (cellulose, lignin, hemi-cellulose) are hardly biodegradable (especially in terms of anaerobic degradation). This is the reason for the low BMP values of substrates which contain fibre in significant amounts (SM). However, prior aerobic treatment may increase methane production, but this was not investigated in the present study. Among the substrates investigated in this study, only SM contains fibre in significant amounts. According to Wu et al. (2017), cellulose and hemi-cellulose are significant components of swine manure. We could not measure fibre content, although the values for $\mathrm{BMP}$ and $\mathrm{AT}_{7}$ for $\mathrm{SM}$ were notably lower than the results for cattle manures.

Based on the research of Krause et al. (2018) and Ventorino et al. (2018), weakly biodegradable carbohydrates are also present in the organic fraction of MSW in notable amounts. However, it is very important to take into consideration that the composition of MSW can be very different in certain regions. Besides this, the organic fraction in MSW is high in most cases - indicating that we can create value and products during the aerobic and / or anaerobic treatment of MSW. Because of its complex composition and heterogeneity, at least mechanical pretreatment is necessary before loading the reactors. Regarding weakly biodegradable compounds (carbohydrates of big molecular 
weight), we suggest mechanical-biological treatment prior to anaerobic digestion. In terms of the methane potential of the MSW substrate investigated in this study $(325.71 \mathrm{Nml} / \mathrm{gVS}, \mathrm{SD}=16.7 \%)$, this type of waste is definitely suitable for biogas production. This experience is totally in line with literature (Liu et al., 2008; Pecorini et al., 2016; Ventorino et al., 2018). On the other hand, municipal solid waste may contain organic and inorganic pollutants, therefore digestate obviously cannot be used in agriculture, nor after composting. Digestate from municipal solid waste must be incinerated. However, nowadays this process can be clean and environmentally safe, moreover, heat power and electricity can be produced from it. The MP values of the investigated substrates are in accordance with literature (Wang et al., 2012, 2017a; Hidalgo and Martín-Marroquín, 2015; Wei et al., 2015; André et al., 2016; Pecorini et al., 2016; Passos et al., 2017; Raj Paudel et al., 2017; Neshat et al., 2017; Siddique et al., 2018).

Correlation - with a good correlation coefficient - between data for respiration intensity and methane potential was not evident and was not written in the literature earlier. A basic difference between the two processes is the presence of oxygen, and therefore the difference in the microbial consortium of the biochemical process, thus it appears that degradation of the biodegradable fraction of the substrates occurred in two different biochemical ways. Despite this, we found linear correlation between the results of the two different examinations. This is an important fact, since respiration intensity tests with OxiTop ${ }^{\circledR}$ take a shorter time (4-7 days) than methane potential tests (at least one month).

\section{Conclusion}

According to the results of our laboratory-scale methane potential tests, the investigated substrates may be suitable for biogas production in full-scale conditions (in some cases, co-digestion may be needed). Hungary does have a significant potential in biogas production which is unutilized presently. The results of this study are especially important with regard to the establishment of a Hungarian scientific database which contains information about the biodegradability and other biological-chemical-physical properties of potential substrate materials. Henceforward we improve and enrich the database with further measurement data of substrates. It is also important to investigate the affects of pretreatments and certain adjustments ( $\mathrm{pH}$, OLR, etc.).

Considering the results of our investigation into correlation, there is a linear relationship between data concerning the aerobic and anaerobic parameters of wastes and agricultural byproducts. This finding can contribute to further developmental endeavors. The aerobic respiration intensity measurements need much less time than biomethane potential tests. Prising the suitability of potential substrates for biogas production can be done more effectively using the linear relationship represented in this study. However further research on this correspondence with bigger number of investigated samples is important (and with more replicates), and also pilot scale experiments are necessary.

Nowadays law on environment and on waste management is getting more and more strict in the European Union, so the results displayed may play an important role to support Hungarian developments on these fields. 
Acknowledgments. Experiments were carried out in the accredited Laboratory for Bioenergetics of the Institute of Agricultural Engineering, National Agricultural Research and Innovation Centre, except for tests for respiration intensity, which were executed in the Laboratory of ProfiKomp Környezettechnika Zrt. Bioprocess Control AMPTSII Equipment is the property of Nawaro Kft. Statistical analysis was done using PAST3 1.0.0.0.

Author Contributions. Zsuzsanna Uveges (Assistant Researcher at NARIC IAE and Ph.D student at SZIU) planned the experiments and took part in executing BMP tests. She did the evaluation of measurement data and drew conclusions. Ádám Ragoncza, Dr. (CEO, Nawaro Inc.) was responsible for sample procurement and took part in executing BMP tests. He also gave consultations about exterior technical experiences. Zsolt Varga (Research Engineer, Profikomp Environmental Technologies Inc.) conducted all of the respiration intensity tests. László Aleksza, Dr. (CEO, Profikomp Environmental Technologies Inc.) ensured professional supervision and coordinating of work.

\section{REFERENCES}

[1] André, L., Ndiaye, M., Pernier, M., Lespinard, O., Pauss, A., Lamy, E., Ribeiro, T. (2016): Methane production improvement by modulation of solid phase immersion in dry batch anaerobic digestion process. Dynamic of methanogen populations. - Bioresource Technology 207: 353-360.

[2] André, L., Pauss, A., Ribeiro, T. (2018): Solid anaerobic digestion: State-of-art, scientific and technological hurdles. - Bioresource Technology 247: 1027-1037.

[3] Angelidaki, I., Ahring, B. (1992): Effects of free long-chain fatty acids on thermophilic anaerobic digestion. - Applied Microbiology and Biotechnology 37: 808-812.

[4] Angelidaki, I., Ahring, B. (1993): Thermophilic anaerobic digestion of livestock waste: the effect of ammonia. - Applied Microbiology and Biotechnology 38: 560-400.

[5] Angelidaki, I., Ahring, B. (1994): Anaerobic thermophilic digestion of manure at different ammonia loads: effect of temperature. - Water Research 28: 727-731.

[6] Binner, E., Böhm, K., Lechner, P. (2012): Large scale study on measurement of respiration activity $\left(\mathrm{AT}_{4}\right)$ by Sapromat and OxiTop. - Waste Management 32: 1752-1759.

[7] Cheng, X. Y., Zhong, C. (2014): Effects of feed to inoculum ratio, co-digestion, and pretreatment on biogas production from anaerobic digestion of cotton stalk. - Energy \& Fuels 28: 3157-3166.

[8] Chiumenti, A., da Borso, F., Limina, S. (2018): Dry anaerobic digestion of cow manure and agricultural products in a full-scale plant: Efficiency and comparison with wet fermentation. - Waste Management 71: 704-710.

[9] Cresson, R., Pommier, S., Béline, F., Bouchez, T., Bougrier, C., Buffiére, P., Pauss, A., Pouech, P., Preys, S., Ribeiro, T. (2015): Results from a French Inter-laboratory Campaign on the Biological Methane Potential of Solid Substrates. - In: 14th World Congress on Anaerobic Digestion AD-14. 15-18 November, Vina del Mar, Chile.

[10] De la Rubia, M. A., Raposo, F., Rincón, B., Borja, R. (2009): Evaluation of the hydrolytic-acidogenic step of a two-stage mesophilic anaerobic digestion process of sunflower oil cake. - Bioresource Technology 100: 4133-4138.

[11] Doublet, J., Boulanger, A., Ponthieux, A., Laroche, C., Poitrenaud, M., Cacho Rivero, J. A. (2013): Predicting the biochemical methane potential of wide range of organic substrates by near infrared spectroscopy. - Bioresource Technology 128: 252-258.

[12] Ebner, J. H., Labatut, R. A., Lodge, J. S., Williamson, A. A., Trabold, T. A. (2016): Anaerobic co-digestion of commercial food waste and dairy manure: characterizing biochemical parameters and synergistics effects. - Waste management 52: 286-294.

[13] Ge, X., Xu, F., Li, Y. (2016): Solid-state anaerobic digestion of lignocellulosic biomass: recent progress and perspectives. - Bioresource Technology 205: 239-249. 
[14] Hidalgo, D., Martín-Marroquín, J. M. (2015): Biochemical methane potential of livestock and agri-food waste streams in the Castilla y León Region (Spain). - Food Research International 73: 226-233.

[15] Holliger, C., Alves, M., Andrade, D., Angelidaki, I., Astals, S., Baier, U., Bougrier, C., Buffiére, P., Carballa, M., de Wilde, V. (2016): Towards a standardization of biomethane potential tests. - Water Science and Technology 74(11): 2515-2522.

[16] Jokela, J. P. Y., Vavilin, V. A., Rintala, J. A. (2005): Hydrolysis rates, methane production and nitrogen solubilization of grey waste components during anaerobic degradation. - Bioresource Technology 96: 501-508.

[17] Kleinheinz, G., Hernandez, J. (2016): Comparison of two laboratory methods for the determination of biomethane potential of organic feedstocks. - Journal of Microbiological Methods 130: 54-60.

[18] Koch, K., Lippert, T., Drewes, J. E. (2017): The role of inoculum's origin on the methane yield of different substrates in biochemical methane potential (BMP) tests. - Bioresource Technology 243: 457-463.

[19] Krause, M. J., Chickering, G. W., Townsend, T. G., Pullammanappallil, P. (2018): Effects of temperature and particle size on the biochemical methane potential of municipal solid waste components. - Waste Management 71: 25-30.

[20] Lesteur, M., Latrille, E., Maurel, V. B., Roger, J. M., Gonzalez, C., Junqua, G. (2011): First steps towards a fast analytical method for the determination of biochemical methane potential of solid wastes by near infrared spectroscopy. - Bioresource Technology 102: 2280-2288.

[21] Li, Y., Park, S. Y., Zhu, J. (2011): Solid-state anaerobic digestion for methane production from organic waste. - Renewable and Sustainable Energy Reviews 15: 821-826.

[22] Li, K., Liu, R., Sun, C. (2015): Comparison of anaerobic digestion characteristics and kinetics of four livestock manures with different substrate concentrations. - Bioresource Technology 198: 133-140.

[23] Liu, C. F., Yuan, X. Z., Zeng, G. M., Li, W. W., Li, J. (2008): Prediction of methane yield at otpimum $\mathrm{pH}$ for anaerobic digestion of organic fraction of municipal solid waste. - Bioresource Technology 99: 882-888.

[24] Malinska, K. (2016): Application of a modified OxiTop respirometer for laboratory composting studies. - Archives of Environmental Protection 42: 56-62.

[25] Neshat, S. A., Mohammadi, M., Najafpour, G. D., Lahijani, P. (2017): Anaerobic codigestion of animal manures and lignocellulosic residues as a potent approach for sustainable biogas production. - Renewable and Sustainable Energy Reviews 79: 308322.

[26] Passos, F., Ortega, V., Donoso-Bravo, A. (2017): Thermochemical pretreatment and anaerobic digestion of dairy cow manure: Experimental and economic evaulation. Bioresource Technology 227: 239-246.

[27] Pecorini, I., Baldi, F., Carnevale, E. A., Corti, A. (2016): Biochemical methane potential tests of different autoclaved and microwaved lignocellulosic organic fractions of municipal solid waste. - Waste Management 56: 143-150.

[28] Raj Paudel, S., Prasad Banjara, S., Kyung Choi, O., Young Park, K., Mo Kim, Y., Woo Lee, J. (2017): Preatreatment of agricultural biomass for anaerobic digestion: Current state and challenges. - Bioresource Technology 245: 1194-1205.

[29] Raju, C. S., Ward, A. J., Nielsen, I., Moller, H. B. (2011): Comparison of near infrared spectroscopy neutral detergent fibre assay and in vitro organic matter digestability assay for rapid determination of biochemical methane potential of meadow grasses. Bioresource Technology 102: 7835-7839.

[30] Riya, S., Suzuki, K., Meng, L., Zhou, S., Terada, A., Hosomi, M. (2018): The influence of the total solid content on the stability of dry-thermophilic anaerobic digestion of rice straw and pig manure. - Waste Management 76: 350-356. 
[31] Siddique, Md. N. I., AbWahid, Z. (2018): Achievements and perspectives of anaerobic co-digestion: A review. - Journal of Cleaner Production 194: 359-371.

[32] Tabatabaei, M., Valijanian, E., Aghbashlo, M., Ghanavati, H., Sulaiman, A., Wakisaka, M. (2018): Prominent Parameters in Biogas Production Systems. - In: Tabatabaei, M., Ghanavati, H. (eds.) Biofuel and Biorefinery Technologies Vol. 6. Biogas. Springer International Publishing AG. Cham, Switzerland.

[33] Triolo, J. M., Ward, A. J., Pedersen, L., Lokke, M. M., Qu, H., Sommer, S. G. (2014): Near Infrared Reflectance Spectroscopy (NIRS) for rapid determination of biochemical methane potential of plant biomass. - Applied Energy 116: 52-57.

[34] Tsapekos, P., Kougias, P., Treu, L., Campanaro, S., Angelidaki, I. (2017): Process performance and comparative metagenomic analysis during co-digestion of manure and lignocellulosic biomass for biogas production. - Applied Energy 185: 126-135.

[35] Tufaner, F., Avsar, Y. (2016): Effects of co-substrate on biogas production from cattle manure: a review. - International Journal of Environmental Science and Technology 13: 2303-2312.

[36] Ventorino, V., Romano, I., Pagliano, G., Robertiello, A., Pepe, O. (2018): Pre-treatment and inoculum affect the microbial community structure and enhance the biogas reactor performance in a pilot-scale biodigestion of municipal solid waste. - Waste Management 73: 69-77.

[37] Wang, X., Yang, G., Feng, Y., Ren, G., Han, X. (2012): Optimizing feeding composition and carbon-nitrogen ratios for improved methane yield during anaerobic co-digestion of dairy, chicken manure and wheat straw. - Bioresource Technology 120: 78-83.

[38] Wang, B., Björn, A., Strömberg, S., Nges, I. A., Nistor, M., Liu, J. (2017a): Evaluating the influences of mixing strategies on the Biochemical Methane Potential test. - Journal of Environmental Management 185: 54-59.

[39] Wang, M., Li, W., Li, P., Yan, S., Zhang, Y. (2017b): An alternative parameter to characterize biogas materials: Available carbon-nitrogen ratio. - Waste Management 62: 76-83.

[40] Wei, Y., Li, X., Yu, L., Zou, D., Yuan, H. (2015): Mesophilic anaerobic co-digestion of cattle manure and corn stover with biological and chemical pretreatment. - Bioresource Technology 198: 431-436.

[41] Wu, J., Hu, Y., Wang, S., Cao, Z., Li, H., Fu, X., Wang, K., Zuo, J. (2017): Effects of thermal treatment on high solid anaerobic digestion of swine manure: Enhancement assessment and kinetic analysis. - Waste Management 62: 69-75. 